\title{
A long-term survivor of clear cell sarcoma-like tumor of the gastrointestinal tract with liver metastasis: a case report
}

\author{
Takuhisa Okada ${ }^{1,2^{*}} \mathbb{D}$, Yasumitsu Hirano ${ }^{1}$, Shintaro Ishikawa ${ }^{1}$, Hiroka Kondo ${ }^{1}$, Toshimasa Ishii ${ }^{1}$ \\ and Shigeki Yamaguchi ${ }^{1}$
}

\begin{abstract}
Background: Clear cell sarcoma-like tumor of the gastrointestinal tract (CCSLTGT) is extremely rare. It is a mesenchymal neoplasm that usually forms in the small intestine of adolescents and young adults, is prone to local recurrence and metastasis, and has a high mortality rate. We report a patient with CCSLTGT with lymph node- and liver metastases, who continues to survive 6 years after initial surgical resection.

Case presentation: A 38-year-old woman presented with lightheadedness. Laboratory analysis revealed anemia (hemoglobin, $6.7 \mathrm{~g} / \mathrm{dL}$ ), and enhanced computed tomography $(\mathrm{CT})$ demonstrated a mass in the small intestine, about $6 \mathrm{~cm}$ in diameter, with swelling of 2 regional lymph nodes. Double-balloon small intestine endoscopic examination revealed a tumor accompanied by an ulcer; the biopsy findings suggested a primary cancer of the small intestine. She was admitted, and we then performed a laparotomy for partial resection of the small intestine with lymph node dissection. Pathologic examination revealed CCSLTGT with regional lymph node metastases. About 3 years later, followup CT revealed a single liver metastasis. Consequently, she underwent a laparoscopic partial liver resection. Histopathologic examination confirmed that the liver metastasis was consistent with CCSLTGT. It has now been 3 years without a recurrence.
\end{abstract}

Conclusion: Repeated radical surgical resection with close follow-up may be the only way to achieve long-term survival in patients with CCLSTGT.

Keywords: Clear cell sarcoma-like tumor of the gastrointestinal tract, Liver metastasis, Long-term survival

\section{Introduction}

Clear cell sarcoma-like tumor of the gastrointestinal tract (CCSLTGT) is a very rare malignant tumor of mesenchymal origin. Histopathologically, CCSLTGT has characteristic spindle-shaped tumor cells that proliferate in sheets, and osteoclast-like multinucleated giant cells are seen $[1,2]$. On immunohistologic staining, S-100 protein and SOX10 are positive but HMB-45 is negative, a finding

\footnotetext{
*Correspondence: t.okd@gunma-u.ac.jp

1 Department of Gastroenterological Surgery, Saitama Medical University International Medical Center, 1397-1, Yamane, Hidaka-City, Saitama-Pref 350-1298, Japan

Full list of author information is available at the end of the article
}

that distinguishes CCSLTGT from malignant melanoma and soft-tissue clear cell sarcoma (CCS). As with CCS, Ewing sarcoma breakpoint region 1 (EWSR1) gene fusion is noted [3, 4]. Because CCSLTGT is a highly malignant tumor, it is important to distinguish it from other mesenchymal neoplasms, such as gastrointestinal stromal tumors (GIST). Local recurrence is common with CCSLTGT, as are lymph node metastases and distant metastases to the liver and lung. These metastases occur rapidly and usually result in death [2]. We report herein a patient with liver metastasis after resection of CCSLTGT of the small intestine. She is alive, without further recurrence, 6 years after her initial surgery. 


\section{Case report}

A 38-year-old Japanese woman presented with lightheadedness. Her medical history was significant for malignant lymphoma at the age of 18 years. Laboratory analysis revealed anemia (hemoglobin, $6.7 \mathrm{~g} / \mathrm{dL}$ ), and enhanced computed tomography $(\mathrm{CT})$ revealed a mass in the small intestine measuring about $6 \mathrm{~cm}$ in diameter, with swelling of 2 regional lymph nodes (Fig. 1). The patient underwent a double-balloon small intestine endoscopy, which revealed a submucosal tumor accompanied by an ulcer (Fig. 2). Examination of the biopsy specimen with immunostaining was negative for malignant lymphoma and GIST, and a very poorly differentiated cancer of the small intestine was suspected. The use of positron emission tomography-CT (PET-CT) confirmed an abnormal accumulation of F-18 fluorodeoxyglucose in the tumor and lymph nodes (Fig. 3). We conferred the diagnosis of a primary malignant tumor of the small intestine with lymph node metastasis. She was admitted and underwent a laparotomy for partial resection of the small intestine with lymph node dissection. The tumor was located in the jejunum and was an ulcerative lesion, measuring $5.8 \times 3.9 \mathrm{~cm}$. Gross examination revealed a white, solid tumor with a clear boundary (Fig. 4a, b). The tumor was located between the muscularis mucosa and the muscularis propria of the small intestine (Fig. 4c, d). There was a fibrous septum separating the sheet-like epithelial cells from a network of eosinophilic cells and an oval-shaped bundle of spindle-like tumor cells. The tumor demonstrated a pseudorosette pattern around several blood vessels and displayed a pseudopapillary growth pattern. Throughout the neoplasm, the tumor cells were associated with numerous osteoclast-type giant cells. On immunohistochemical examination (Table 1), the tumor cells stained positive for the anticytokeratin antibodies AE1 and AE3 (on part of the surface layer) and for S-100, and partially positive for the neural cell adhesion molecule (CD56) and synaptophysin. The cells stained negative for anticytokeratin (CAM 5.2), lymphocyte common antigen (CD45), desmin, $\alpha$-smooth muscle actin (a-SMA), c-kit, CD34, HMB-45, melan-A, chromogranin A, CD1a, and CD21. The osteoclast-type giant cells were positive for CD68. Fluorescence in situ hybridization (FISH) using an EWSR1 probe revealed a split signal in the tumor cells: seemingly an EWSR1 gene fusion (Fig. 5). Taken together, these results yielded a diagnosis of CCSLTGT. Metastases were found in 3 of 20 lymph nodes.

About 3 years later, follow-up CT revealed a single liver metastasis (Fig. 6a). The results of gadoxetic acidenhanced magnetic resonance imaging (EOB-MRI) and PET-CT were also suggestive of liver metastasis (Fig. 6bd). Consequently, the patient underwent a laparoscopic partial liver resection. Histopathologic examination

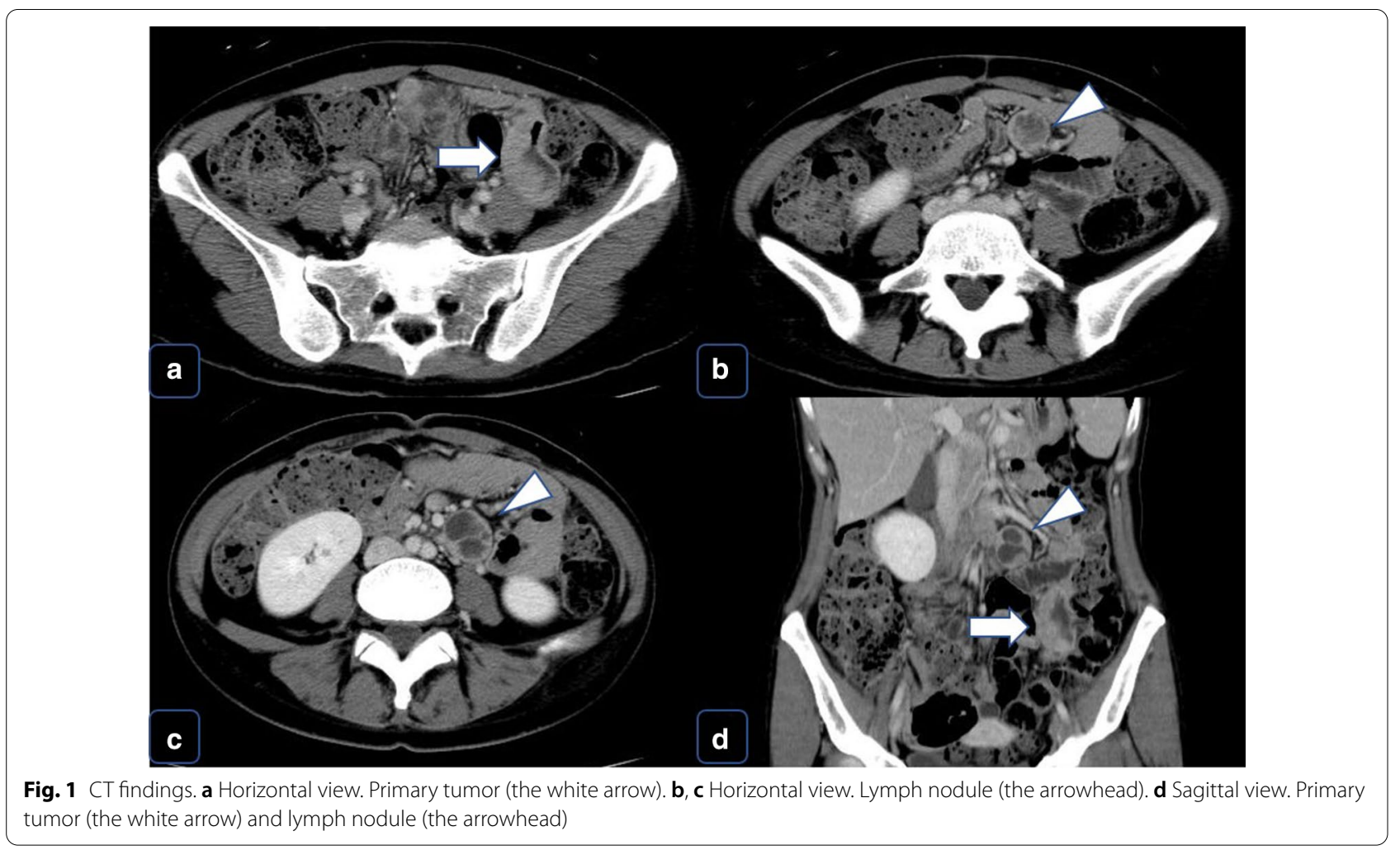




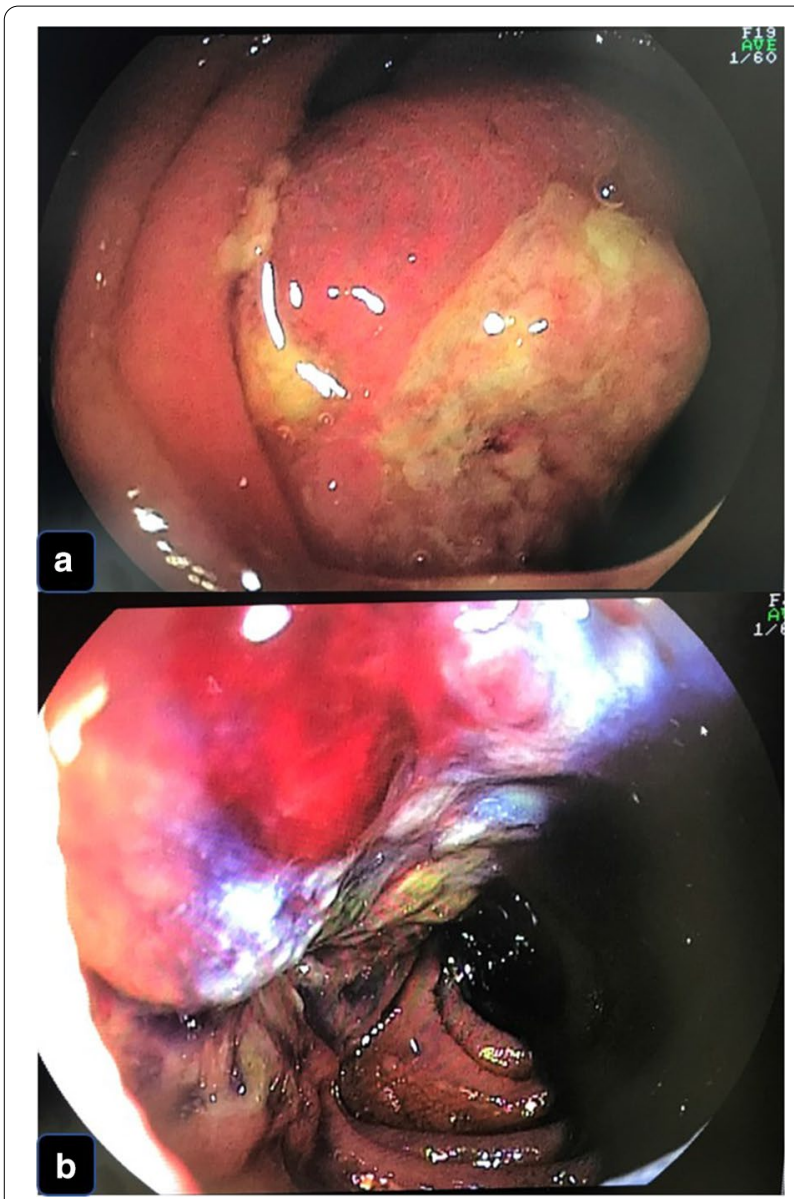

Fig. 2 Findings of double-balloon endoscopy. $\mathbf{a}$, b Primary tumor looked like submucosal tumor accompanied by an ulcer

revealed that the liver metastasis was consistent with CCSLTGT (Fig. $7 \mathrm{a}-\mathrm{c}$ ). It has now been 3 years since this procedure, and follow-up CT every 3 to 6 months has shown no evidence of recurrence.

\section{Discussion}

The entity of CCSLTGT was first described by Zambrano et al. in 2003, when they reported 6 patients with a disease they called "osteoclast-rich tumor of the gastrointestinal tract", with features resembling those of soft-tissue CCS [1]. This tumor is relatively rare and shows no preference for sex. Many patients are in their $30 \mathrm{~s}$ and $40 \mathrm{~s}$, but there are reports of patients ranging in age from 15 to 85 years [2]. It is most common for CCSLTGT to develop in the small intestine, but it has also been reported in the stomach and colon [2]. Since it is a malignant tumor originating from the interstitium of the wall of the gastrointestinal tract, it must be differentiated from GIST, synovial sarcoma, and malignant peripheral nerve sheath tumors [3]. The etiology of

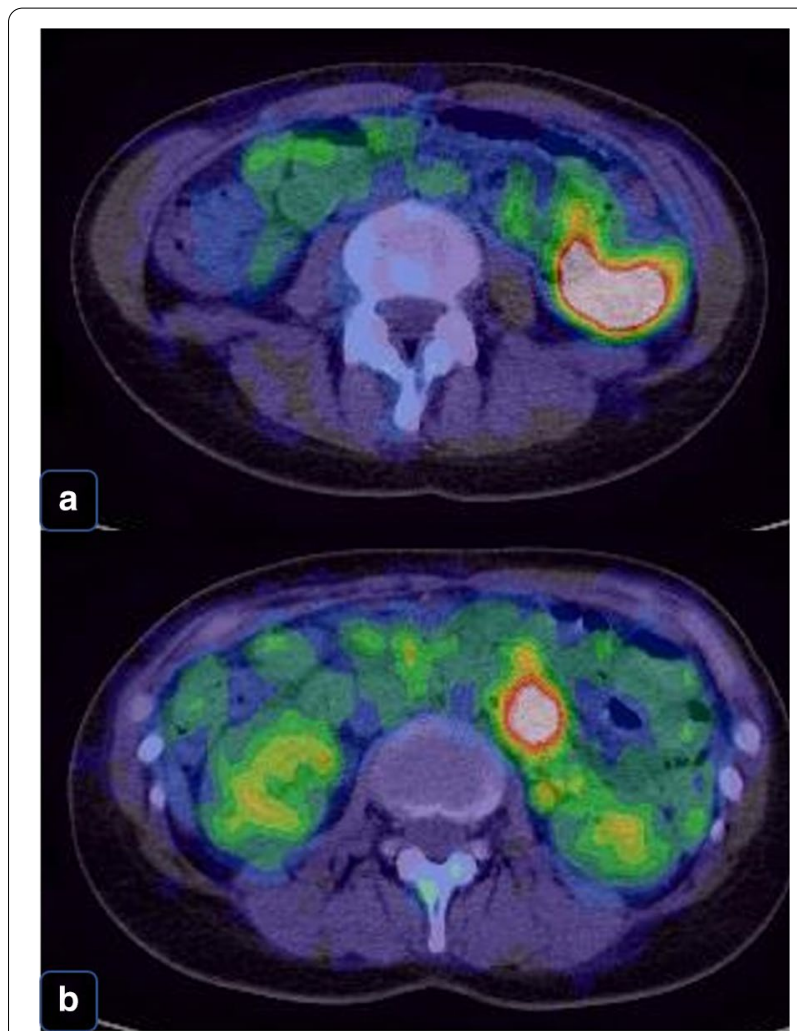

Fig. 3 PET-CT confirmed an abnormal accumulation of F-18 fluorodeoxyglucose in the tumor and lymph nodes. a Primary tumor's accumulation. b Lymph nodule's accumulation

CCSLTGT is unknown, but it has been suggested that radiotherapy may be a precipitating factor in the later development of the disease. Two cases of secondary malignancy after irradiation of neuroblastoma in infancy have been reported $[16,20]$. Our case has been treated for malignant lymphoma in the past, but the details of the treatment are unknown. It is not clear whether the treatment was related to the development of CCSLTGT, and there are no reports on the relationship between both malignant lymphoma and CCSLTGT. Scattered osteoclast-like multinucleated giant cells are characteristic of CCSLTGT. Tumor cells stain positive for vimentin, S-100 protein, and SOX10; neuroendocrine markers such as CD56, synaptophysin, and NSE may also be positive. Melanocytic markers such as HMB-45 and melanA, which are positive in soft-tissue CCS, are negative in CCSLTGT, as are c-kit, CD34, desmin, $\alpha$-SMA, and keratin. Both our current patient and our previously reported patient $[1,2,4,9,14,15,17-19,21]$ had osteoclast-like multinucleated giant cells that were positive for CD68, indicating increased responsiveness. Zambrano et al. [1] report a single patient with chromosomal translocation involving EWSR1, similar to that seen with 


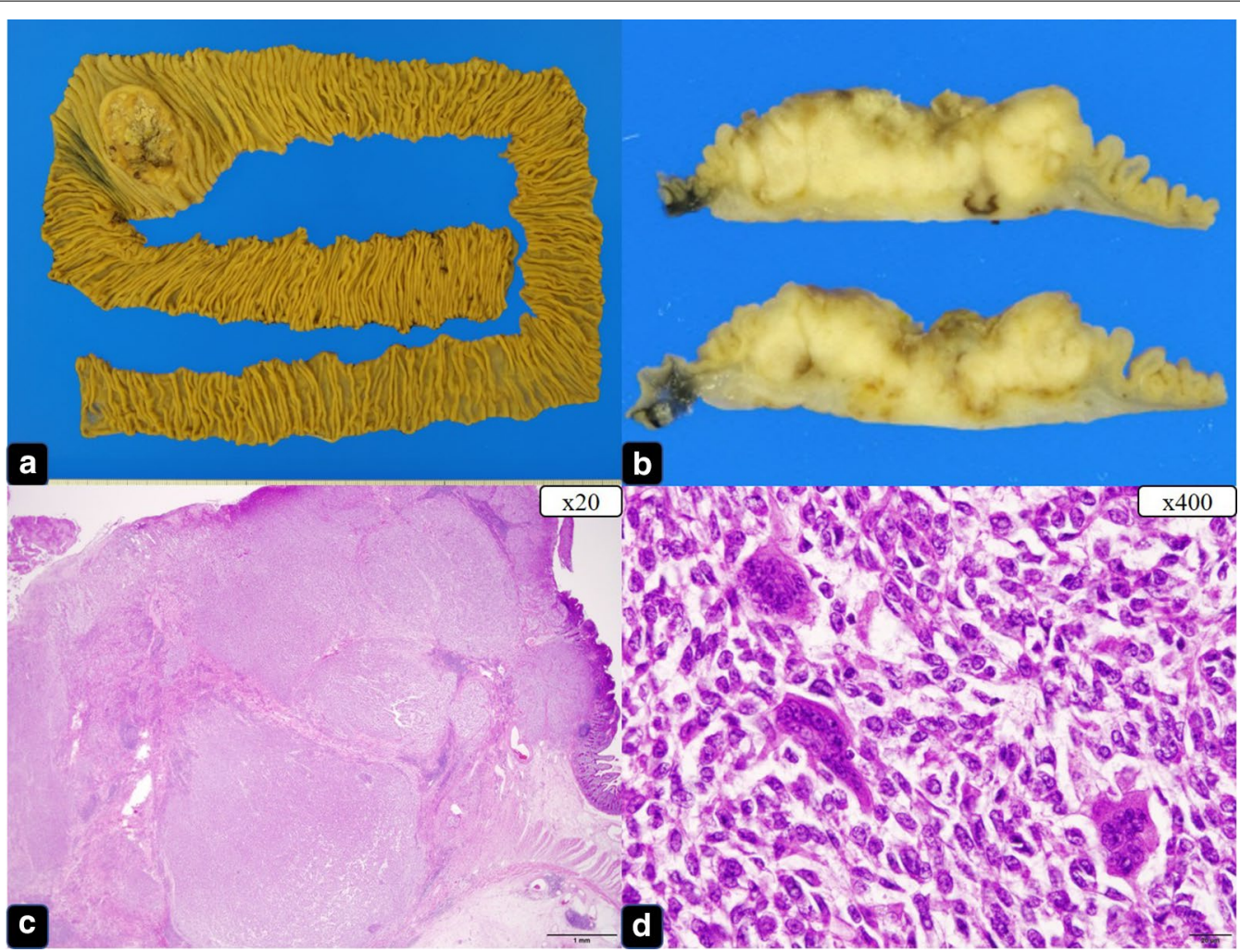

Fig. 4 The tumor was located in the jejunum and was an ulcerative lesion. a Resected specimen (jejunum). b Cut surface, white solid tumor with clear boundary. c HE stain, low-power view. d HE stain, high-power view

Table 1 The list of immunohistochemical examination for our case

\begin{tabular}{ll}
\hline Positive & Negative \\
\hline AE1/AE3 (part of the surface layer) & CAM 5.2, HMB-45, Melan-A \\
S-100 & Desmin, chromogranin \\
CD 56 (partial) & a-SMA, c-kit \\
Synaptophysin (partial) & CD1a, CD21, CD34, CD45 \\
CD68 (only osteoclast-type giant cell) & \\
\hline
\end{tabular}

CCS. $\mathrm{Cu}$ et al. [4] and Stockman et al. [3] also report patients with CCSLTGT and EWSR gene fusion similar to that seen with CCS. A highly malignant tumor is considered to confer a poor prognosis; many patients die within 36 months, and more than half have local lymph node metastasis at the time of diagnosis. The most common site of distant metastasis is the liver, and curative treatment involves only surgical resection of any metastases. There are 43 reported patients with CCSLTGT of the small intestine to date: 21 men and 22 women, including our previously reported patient (Table 2).

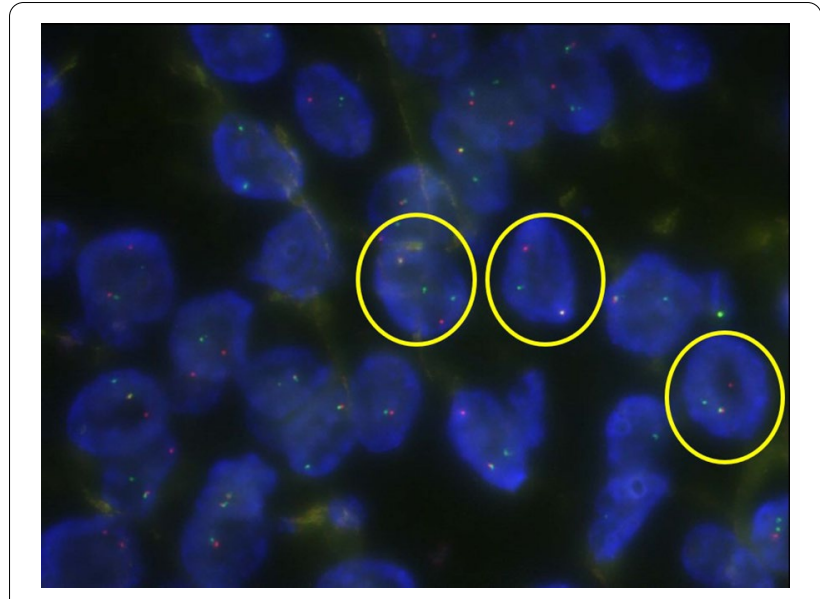

Fig. 5 EWSR1-FISH positive lesion (yellow circle)

The tumor location was the jejunum in 11 patients, the ileum in 24 patients, and was unknown in 8 patients. The sites of metastasis at initial diagnosis include the lymph nodes $(n=17)$, liver $(n=6)$, peritoneum $(n=3)$, and lungs $(n=2)$. Of the 43 patients, curative resection 


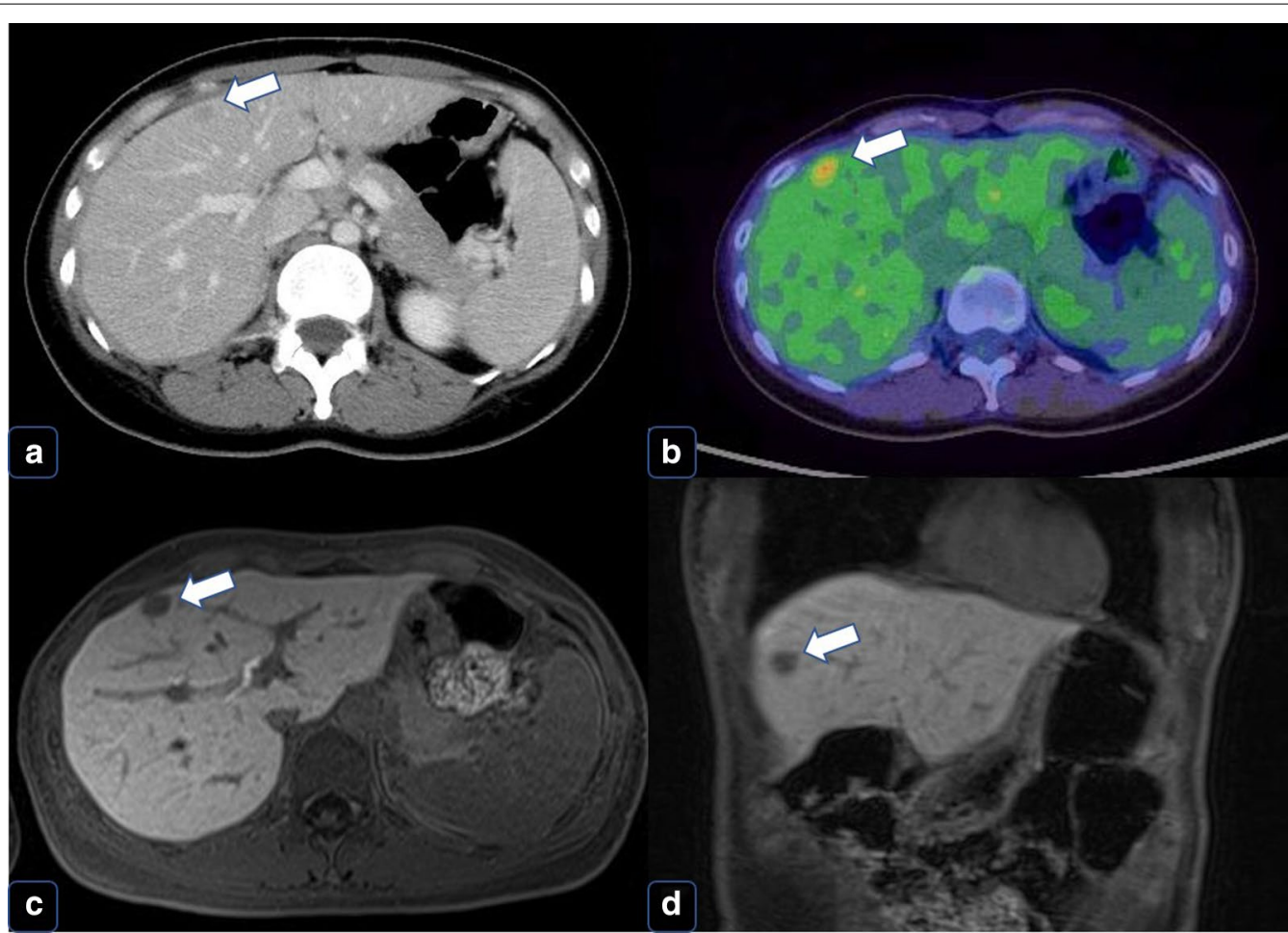

Fig. 6 Findings at a single liver metastasis. a CT. Horizontal view. Liver metastasis (the white arrow). b PET (the white arrow). c EOB-MRI. Horizontal view (the white arrow). d EOB-MRI. Sagittal view (the white arrow)

was performed in $30(69.8 \%)$, and among them, recurrence occurred in 18 (60.0\%). The mean period between initial surgery and recurrence was 20.0 months. However, 2 recurrences occurred over 5 years after the initial surgery, emphasizing the importance of long-term follow-up. The recurrence sites were the liver $(n=11)$, lymph nodes $(n=5)$, peritoneum $(n=4)$, lung $(n=1)$, ovary $(n=1)$, omentum $(n=1)$, and pleura $(n=1)$. Local recurrence and intra-abdominal recurrence occurred in 1 patient each. Of the 18 patients with recurrence, treatment after recurrence included surgery-alone $(n=4)$, chemotherapy-alone $(n=2)$, surgical resection with chemotherapy $(n=1)$, no treatment $(n=1)$, and unknown details $(n=10)$. All five patients with surgical resection survived within the observation period, among which two patients with curative resection were diseasefree and the other three were in the tumor-bearing. Only three patients received chemotherapy. Platinum-based chemotherapy was performed in one patient and details were unknown in two. Two patients with chemotherapyalone died in 13 and 16 months after recurrence, and their survival times indicated the non-effectiveness of this therapy. Eleven of the reported patients are known to be dead of their disease, but data on mortality are missing for 17 patients. Of the remaining 15 patients, 9 have no evidence of disease, and 6 are alive with disease. Curative surgical resection is the only possible cure treatment for recurrence of CCSLTGT. Chemotherapy has not been reported to be effective, and there are no established chemotherapy regimens until now. In terms of postoperative adjuvant chemotherapy, mainly ifosfamide and doxorubicin were administrated, however, its efficacy has not been proved [28]. Only 2 patients, including the patient in this report, survived for over 



Fig. 7 The single metastatic tumor was located in the liver. a Resected specimen (liver) and cut surface, white solid tumor with clear boundary. $\mathbf{b}$ HE stain, low-power view. c HE stain, high-power view

5 years without evidence of disease; both of them had tumor recurrence that was treated with surgical resection. Repeated radical surgical resection appears to be the only way to achieve long-term survival in patients with CCSLTGT, a neoplasm that easily metastasizes in a short period. It is important to follow patients with contrast $\mathrm{CT}$ every 3 months to ensure that radical resection of any recurrence can occur in a timely fashion.

\section{Conclusions}

We report a patient with CCSLTGT with lymph node and liver metastases, who continues to survive 6 years after the initial surgical resection. It is important to follow patients with contrast CT every 3 months to ensure that radical resection of any recurrence can occur in a timely fashion. 


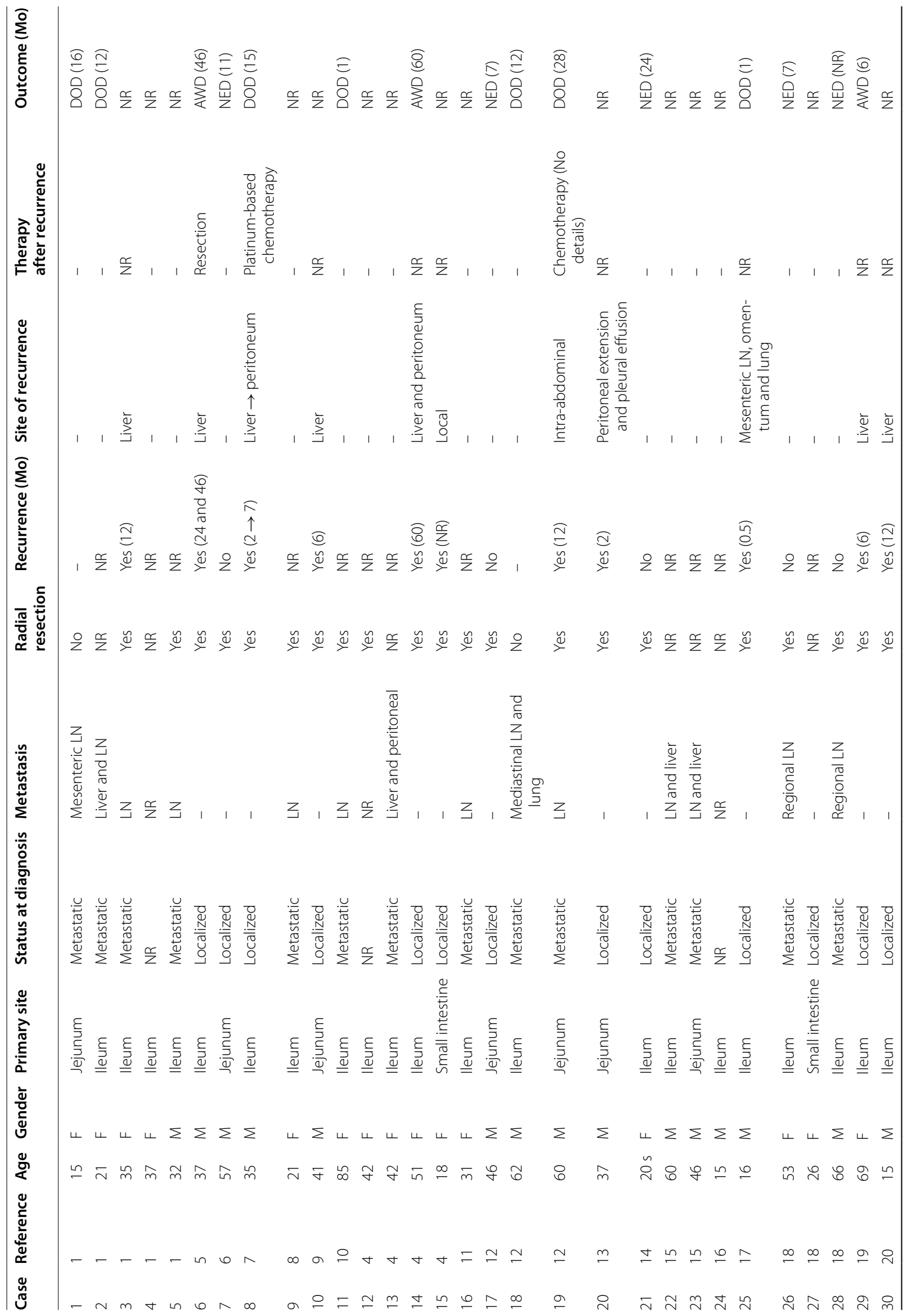




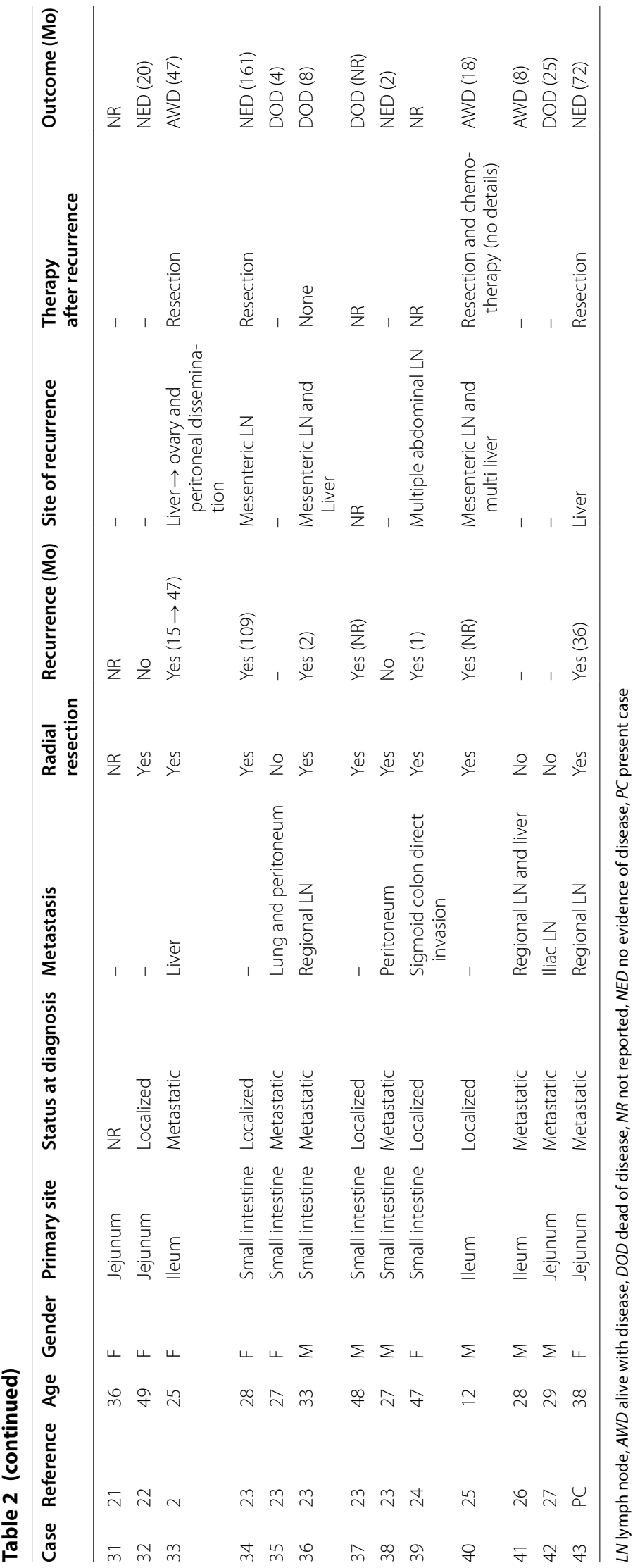




\begin{abstract}
Abbreviations
CCSLTGT: Clear cell sarcoma-like tumor of the gastrointestinal tract; CT: Computed tomography; CCS: Clear cell sarcoma; EWSR1: Ewing sarcoma breakpoint region 1; GIST: Gastrointestinal stromal tumors; PET-CT: Positron emission tomography-CT; EOB-MRI: Gadoxetic acid-enhanced magnetic resonance imaging; CD56: The neural cell adhesion molecule; CAM 5.2: Anticytokeratin; CD45: Lymphocyte common antigen; a-SMA: a-Smooth muscle actin; FISH: Fluorescence in situ hybridization.
\end{abstract}

\section{Acknowledgements}

None.

\section{Authors' contributions}

TO and YH wrote the manuscript. SY supervised the case. All other authors reviewed the manuscript. All authors read and approved the final manuscript.

\section{Funding}

No funding was received for this case series.

\section{Availability of data and materials}

Data sharing is not applicable to this article, since datasets were neither generated nor analyzed for the case series.

\section{Ethics approval and consent to participate}

Not applicable.

\section{Consent for publication}

Written informed consent was obtained from the patients for the publication of this report.

\section{Competing interests}

The authors declare that they have no competing interests.

\section{Author details}

${ }^{1}$ Department of Gastroenterological Surgery, Saitama Medical University International Medical Center, 1397-1, Yamane, Hidaka-City, Saitama-Pref 350-1298, Japan. ${ }^{2}$ Department of General Surgical Science, Gunma University Graduate School of Medicine, 3-39-22 Showa-Machi, Maebashi-City, Gunma-Pref 371-8511, Japan.

Received: 18 June 2020 Accepted: 23 September 2020

Published online: 06 October 2020

\section{References}

1. Zambrano E, Reyes-Mugica M, Franchi A, Rosai J. An osteoclast-rich tumor of the gastrointestinal tract with features resembling clear cell sarcoma of soft parts: reports of 6 cases of a GIST simulator. Int I Surg Pathol. 2003;11:75-81.

2. Gulcin Y, Mine G, Ozgur M, Semen O, Yersu K. Clear cell sarcoma-like tumor of the gastrointestinal tract: a case report and review of the literature. Int J Surg Pathol. 2015;23(1):61-7.

3. Stockman DL, Miettinen M, Suster S, Spagnolo D, Dominguez-Malagon $\mathrm{H}$, Hornick JL, et al. Malignant gastrointestinal neuroectodermal tumor: clinicopathologic, immunohistochemical, ultrastructural, and molecular analysis of 16 cases with a reappraisal of clear cell sarcoma-like tumors of the gastrointestinal tract. Am J Surg Pathol. 2012;36:857-68.

4. Antonescu CR, Nafa K, Segal NH, Dal Cin P, Ladanyi M. EWS-CREBl:a recurrent variant fusion in clear cell sarcoma-association with gastrointestinal location and absence of melanocytic differentiation. Clin Cancer Res. 2006;12:5356-62.

5. Donner LR, Trompler RA, Dobin S. Clear cell sarcoma of ileum the crucial role of cytogenetics for the diagnosis. Am J Surg Pathol. 1998;22:121-4.

6. Achten R, Debiec-Rychter M, De Wever I, Sciot R. An unusual case of clear cell sarcoma arising in the jejunum highlights the diagnostic value of molecular genetic techniques in establishing a correct diagnosis. Histopathology. 2005;46:472-4.

7. Taminelli L, Zaman K, Gengler C, Peloponissios N, Bouzourene H, Coindre $J \mathrm{M}$, et al. Primary clear cell sarcoma of the ileum: an uncommon and misleading site. Virchows Arch. 2005;447:772-7.
8. Venkataraman G, Quinn AM, Williams J, Hammadeh R. Clear cell sarcoma of the small bowel: a potential pitfall. Case Report. 2005;113:716-9.

9. Friedrichs N, Testi MA, Moiraghi L, Modena P, Paggen E, Plotner A, et al. Clear cell sarcoma-like tumor with osteoclast-like giant cells in the small bowel: further evidence for anew tumor entity. Int J Surg Pathol. 2005;13:313-8.

10. Covinsky M, Gong S, Rajaram V, Perry A, Pfeifer J. EWS-ATF1 fusion transcripts in gastrointestinal tumors previously diagnosed as malignant melanoma. Human Pathol. 2005;36:74-81.

11. Comin CE, Novelli L, Tornaboni D, Messerini L. Clear cell sarcoma of the ileum: report of a case and review of literature. Virchows Arch. 2007:451:839-45.

12. Lyle PL, Amato CM, Fitzpatrick JE, Robinson WA. Gastrointestinal melanoma or clear cell sarcoma? Molecular evaluation of 7 cases previously diagnosed as malignant melanoma. AM J Surg Pathol. 2008;32:858-66.

13. Abdulkader I, Cameselle-Tejieiro J, de Alava E, Ruiz-Ponte C, Used-Aznar MM, Forteza J. Intestinal clear cell sarcoma with melanocytic differentiation and EWS [corrected] rearrangement: report of a case. Int J Surg Pathol. 2008;16:189-93.

14. Terazawa K, Otuka H, Morita N, Yamashita K, Nishitani H. Clear cell sarcoma of the small intestine detected by FDG-PET/CT during comprehensive examination of an inflammatory reaction. J Med Invest. 2009;56:70-5.

15. Zucman J, Delattre O, Desmaze C, Epstein AL, Stenmann G, Speleman $F$, et al. EWS and ATF-1 gene fusion induced by $\mathrm{t}(12 ; 22)$ translocation in malignant melanoma of soft parts. Nat Genet. 1993;4:341-5.

16. Balkaransingh P, Saad SA, Govil SC, Thind PK, Vallance CM, Weiss AR. Clear cell sarcoma of the gastrointestinal tract presenting as a second malignant neoplasm following neuroblastoma in infancy. Padiatr Blood Cancer. 2012;58:481-2.

17. Granville L, Hicks J, Popek E, Dishop M, Tatevian N, Lopez-Terrada D. Visceral clear cell sarcoma of soft tissue with confirmation by EWS-ATF1 fusion detection. Ultrastruct Pathol. 2006:30:111-8.

18. Shenjere P, Salman WD, Singh M, Mangham DC, Williams A, Eyden BP, et al. Intra-abdominal clear cell sarcoma: a report of 3 cases, including 1 case with unusual morphological features, and review of the literature. Int I Surg Pathol. 2012;20:378-85.

19. D'Amico FE, Ruffolo C, Romeo S, Massani M, DeiTos AP, Bassi N. Clear cell sarcoma of the ileum: report of case and review of the literature. Int I Surg Pathol. 2012;20:401-6.

20. Yang JC, Chou AJ, Oeffinger KC, La Quaglia MP, Wolden AL. Clear cell sarcoma of the gastrointestinal tract after very low dose therapeutic radiation therapy: a case report. J Pediatr Surg. 2012;47:1943-5.

21. Suarez-Vilela D, Izquierdo FM, Tojo-Ramallo S, Riera-Velasco J, Escobar-Stein J. Malignant gastrointestinal nueroectodermal tumor showing overlapped immunophenotype with synovial sarcoma CD99 and Sox10 antibodies are useful in differential diagnosis. Am J Surg Pathol. 2012;36:1905-8.

22. Lasithiotakis K, Protonotarios A, Lazarou V, Tzardi M, Chalkiadkis G. Clear cell sarcoma of the jejunum: a case report. World J Surg Oncol. 2013;11:17.

23. Michela L, Khin T, Jonathan N, Florian P, Christina M, Cyril F, et al. Clear cell sarcoma-like tumor of the gastrointestinal tract: Clinical outcome and pathologic features of a molecularly characterized Tertiary center case series. Anticancer Res. 2018;38:1479-83.

24. Kato T, Ichihara S, Gotoda H, Muraoka S, Kubo T, Sugita S, et al. Imprint cytology of clear cell sarcoma-like tumor of the gastrointestinal tract in the small intestine: a case report. Diagn Cytopathol. 2017;45:1137-41.

25. Wolak P, Wincewicz A, Czauderna P, Spałek M, Kruczak A, Urbaniak-Wąsik $S$, et al. Malignant gastrointestinal neuroectodermal tumor (clear cell sarcoma-like tumor of the gastrointestinal tract) of the small intestine in a 12-year-old boy. Dev Period Med. 2018;22:358-63.

26. Askan G, Kombak FE, Seven IE, Basturk O. Clear cell sarcoma-like tumor of the gastrointestinal tract. J Gastrointest Cancer. 2019;50:651-6.

27. Sonai MK, Rastogi S, Madhusudhan KS, Gupta SD, Das P. Clear cell sarcoma like tumor of gastrointestinal tract: Experience of three cases and review of literature. Indian J Pathol Microbiol. 2020;63:90-5.

28. Washimi K, Takagi M, Hisaoka M, Kawachi K, Takeyama M, Hiruma T, et al. Clear cell sarcoma-like tumor of the gastrointestinal tract: a clinicopathological review. Pathol Int. 2017;67:534-6.

\section{Publisher's Note}

Springer Nature remains neutral with regard to jurisdictional claims in published maps and institutional affiliations. 